Issue no. $25 / 2018$

\title{
WHAT SHOULD POLITICIANS KNOW ABOUT BRIDGING THE GAP BETWEEN DECIDERS AND RECEIVERS?
}

\author{
Shula MENACHEM ${ }^{18}$, PhD
}

\section{DOI:10.24193/OJMNE.2018.25.05}

\begin{abstract}
This article reviews the gap between declared policy and its implementation in the field of social services and examine the nature of the gap. The article will suggest an original and unique approach to bridge the gap, an approach that is based on the findings and conclusions of the doctoral dissertation entitled "An Evaluation of Social Services Policy in Israel: from Deciders to Receivers", under the supervision of Professor Dr. Vasile Puscas at Babes-Bolyai - University Cluj-Napoca, Faculty of European Studies

The findings stress the concept of "new politics" (Pierson, 2001) and the need to acknowledge that decision making is a process that involves participants both inside and outside the political arena.
\end{abstract}

Keywords: deciders, receivers, new politics, collaboration, partnerships

\section{Introduction}

In the public services, we are witnessing a demand for efficient management, pressures to decentralize and delegate, demands to include civil society in formulating policy, demographic changes, increase in life expectancy, etc. Due to these changes, many countries, Israel amongst them, have had to adjust and reexamine their social services policy. In other words, the intensity of these changes has constituted the basis for the social services reform in Israel on the one hand, and raised a question regarding policy implementation and the gap between deciders and receivers on the other. Yin (1992) pointed out the need to evaluate public sector programs and projects in which great resources and thoughts are invested, using research measurements and explaining the results of actions, programs and more. This

\footnotetext{
18 Social Worker, Director of Social Services Department, Municipality of Karmiel (a local authority in the North of Israel) and Chair of the Local Authorities Social Services Directors Association in Israel.
} 
argument was the foundation of the considerations determining the aims of research described in this article.

As a longstanding employee in public services, and a partner in a number of national forums to formulate policy, new programs, field instructions and more, I have noticed that there is not enough reference to the issue of evaluating and measuring the performance standards of diverse decisions, whether referring to policies or programs.

This article will review the gap between declared policy (i.e. the deciders) and its implementation (i.e. the receivers), examine the nature of this gap and suggest a unique approach to bridge the gap in order to accomplish more adaptive policy with better practicability for implementation. The article is based on the findings and conclusions of the doctoral dissertation entitled "An Evaluation of Social Services Policy in Israel: from Deciders to Receivers", under the supervision of Professor Dr. Vasile Puscas.

The research found that the gap between deciders and receivers is structured and comes into being as early as the policy formulation process, continuing into the implementation stage. By processing the findings and conclusions, a new model is proposed as a means for narrowing the gap, when considering new policy.

Politicians should be aware of changes that have taken place in both the political and public space and embrace new tools, language and perceptions using three key processes suggested in the model: 1. Recognizing 2. Mapping 3. Steering.

\section{Theoretical Framework}

Weiss-Gal and Gal (2011) and Starke (2006) consolidated the various existing theories in social services policy making and implementation into four groups of core theories: functional/neo-functional approaches, political approaches/conflict theories, idea based approaches and institutional approaches. The research employed two different key theories: "Stakeholders Analysis" and the complex adaptive approach (CAS). The stakeholders approach is an approach that has gradually gained a significant place in policy research, analysis and implementation. It broadens perspectives with regard to a political system in the process of making and implementing policy by examining sub-systems that affect these processes in the public space: players in the decision-making arena, beliefs 
Issue no. $25 / 2018$

motivating them, structures created in creating agreement based coalitions, mobilizing resources - all to influence decision makers (Weibel, 2007).

To supplement the stakeholders' approach the research used the CAS approach as well. According to this approach, change is characterized by blurring boundaries between policy makers, stakeholders and consumers, and the influence of each, complex interactions among all stakeholders, a rapid pace of change and more (Schneider \& Somers, 2006). The CAS approach offers innovative tools that are adjusted to understanding and analyzing implementation and assimilation of change and policy in the dynamic environment in which we live. Dooley (1997) defined the main elements of this approach and claimed it uses systematic investigation to present a multi-layered, multi-disciplinary and vague reality. CAS behavior develops according to two key principles: order is not accomplished through hierarchy and authority, and is not pre-planned but rather comes into being. The second principle refers to the fact that the state of the system is irreversible and unpredictable.

\section{Conceptual Framework}

The conceptual framework for the research, as presented in the figure below, expresses the main aspects of the Stakeholders' Approach (Weibel, 2007), the CAS approach (Dooley, 1997) and the Kraft and Furlong's (2010) cyclical model of policy making. This framework presents the connections between players and processes with regard to policy making, implementation and gaps on the way to implementation. 


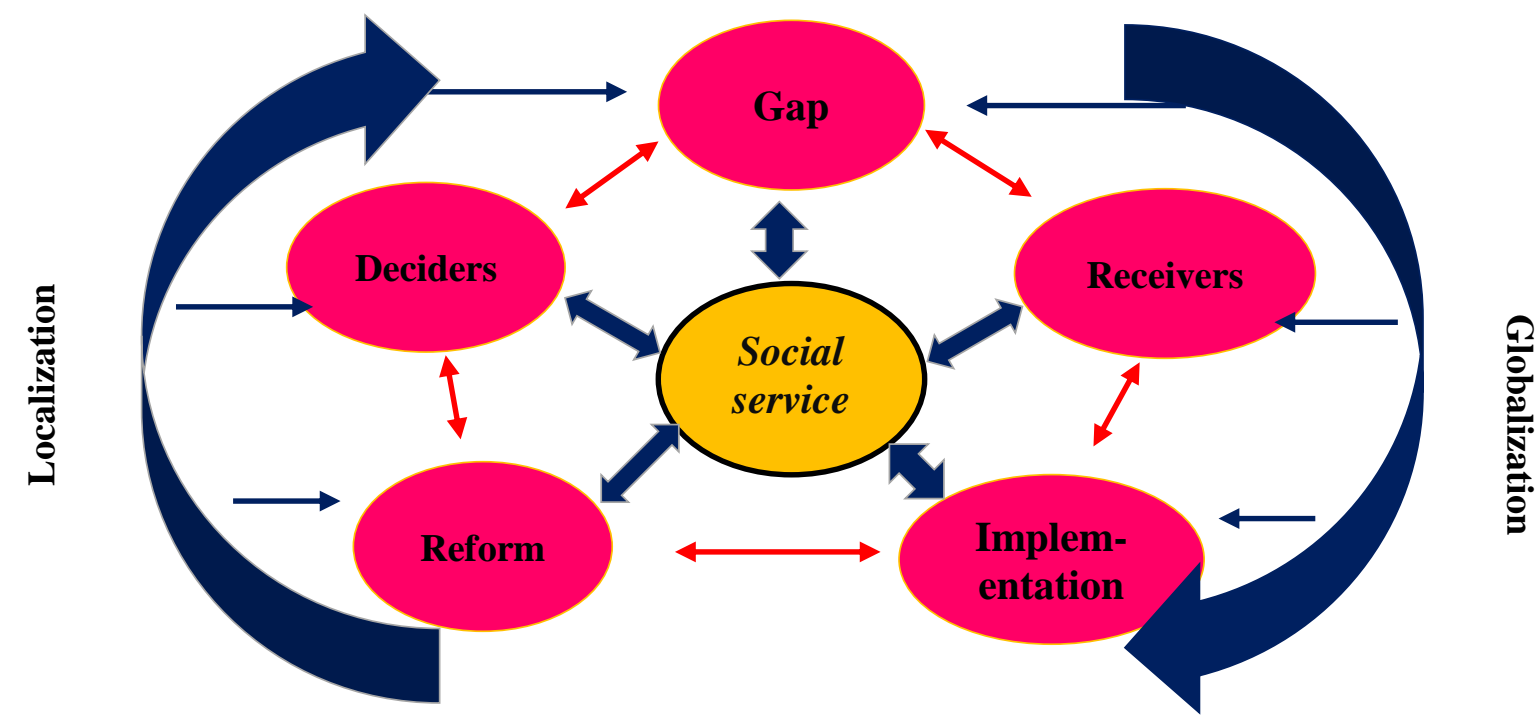

Figure 1: Dynamic Bidirectional \& Multidirectional Process

The concept of Social Service Policy (SSP) is in the center of the figure, because it was the heart of the research. The research sought to examine the components of social services policy on the one hand, and its implementation on the other. The research examined the gap between policy and implementation as expressed by deciders and receivers. The gap is actually developed in the course of implementation. The two theories of localization and globalization hover over the entire framework of concepts, which both influence and are influenced by one another, theories with direct affiliation to each concept and naturally, mutual influences.

In the conceptual framework, one can see the system of ties and interactions. This system is multi-dimensional, multi-directional and multi-levelled, when multiple power streams mutually influence all components, which influence one another: each component influences and is influenced, and creates a new reality as presented in the CAS approach, in an ongoing dynamic and active process. When these components are joined and act in the way described here, a synergy is created, which allows for the formation of social services policy in the global world. 
Issue no. $25 / 2018$

\section{Methodology}

The research was carried out using the qualitative paradigm and the case study approach to the issue of Social Services Reform and its implementation. The overall aim of the research was to examine whether there is a gap between declared policy i.e. deciders and its implementation i.e. receivers, to understand and identify the gap's components and reasons. The secondary aim of the research was to develop an approach and operating means that capable of bridging the gap between stated policies and their practical implementation in the field of social services, in order to reach maximal and optimal implementation of decisions and policies.

The data was collected in the field, from policy makers, mid-level professionals, bureaucrats and receivers, as well as from official documents published on the matter. Patton (2002) stated that all samples in qualitative research fall under the broad umbrella of the concept "purposeful sampling", since the actual nature of qualitative observation is in-depth focus on relatively small number and sometimes single cases that are deliberately chosen.

Based on these considerations the research population was chosen and included deciders and receivers as detailed below:

- Senior post holders, both currently and in the past, in the Ministry of Social Affairs and Social Services in Israel.

- Chair of the National Union of Social Workers in Israel.

- $\quad$ Mayors who, by law are responsible for the implementation of social services policies in local authorities.

The receivers consist of two groups of two types of clients: policy clients are the professional in the field, who are required to apply policy, and the direct clients who are social services' consumers, the result of policy.

- Heads of Social Service Departments in local authorities who represent street level workers/

- $\quad$ Receivers, clients of social services, the services users themselves. 
Issue no. $25 / 2018$

Three groups of clients were chosen: seniors, people with special needs and people living in poverty and exclusion. The reason for choosing these three population groups was because they are mentioned in official policy documents as target populations with high priority, as well as being mentioned in the literature - as dominant groups in the population because of the dramatic increase in worldwide life expectancy and because of the global increase in demands for equal rights and services for people with special needs, economic crises and changes in labor markets. Choosing participants for the focus groups adhered to "convenience sampling" techniques (Miles \& Huberman, 1994) so as to reach participants who were easiest to reach and known to be comfortable in open and frank discussions as well as verbal and willing to cooperate.

Three key questions were formulated as the research questions:

a. What are the components that constitute social services policy in Israel?

b. What gap can be found between official declared policy and its implementation?

c. What constitutes the gap and how can it be bridged?

Creswell (2009) argued that the most widespread and appropriate tools for qualitative research are: interviews, documents, pictures, text analysis and analysis according to patterns and categories. The research employed 3 different tools: document analysis, semi-structured in-depth interviews, and focus groups as they were found to best suit the research aims and questions. Use of three different tools was meant both to strengthen (triangulation) and enrich the findings arising from the data collection stage and examining findings. Data collection in this research was from diverse sources, using different tools to reflect a variety of opinions and perceptions with regard to policy, reform and implementation on the one hand, and acquire a broad and rich picture of data on the other. The data analysis process is the heart of qualitative research and allows researchers the transition between reporting and knowledge, by creating order and links between actions and phenomena in structuring information and providing interpretations and meaning to texts (Creswell, 2014; Shkedi, 2003; Tzabar BenYehoshua, 2016).

In this study, content analysis was carried out on the data collected from interviews, focus groups and official documents. The work process included extricating themes allocated to categories (Shkedi, 2014) aligned and congruent with the research questions: The analysis 
Issue no. $25 / 2018$

process was systematic and carried out according to the stages proposed by Kacen and Krumer-Nevo (2010): holistic reading of the data, initial mapping: organizing the data and reducing it, 'breaking' the data down into small units of analysis, coding and naming: restructuring the data into categories and theoretical conceptualization, holistic rereading, verifying findings and the last stage - writing.

\section{Findings}

The findings presented below are part of the comprehensive research findings. They focus on the implications with regard to policy making and what politicians should learn and know about it.

Findings Emerging from Research Question No 1: What are the components that constitute social services policy in Israel?

Ideology - this component refers to existing economics in England from which the model of mixed welfare is derived, in which service funding is mixed and includes the private and business sectors, the existence of selective and universal services simultaneously, an ongoing process of decentralization and delegating authority to local government, public and private bodies, and of course anchoring the principles of welfare in broad legislation, international regulations and treaties

Emphasis on needs - this component defines clients as consumers, a definition that places the client in a position of having the right to be a partner in choosing services, their acquisition and thus, the government has to provide accessibility to services and make information available, together with creating quality services that strive for excellence and setting standards whilst providing ongoing inspection with regard to the nature and quality of services presented to clients.

\section{Multiculturalism and Globalization influences}

Content analysis of the 2014-18 SSP in Israel document revealed that multiculturalism, meaning culturally sensitive work recognizing unique groups is a key component underlying SSP in the state of Israel. "Develop culturally competent services, adjust professional interventions of social services to the cultural background of clients and 
Issue no. $25 / 2018$

instruct workers on cultural sensitivity and use of language they understand" (translated from Hebrew p.14)."

Findings Emerging from Research Question No.2: What gap can be found between official declared policy and its implementation?

A summary of the findings gathered from interviews in response to research question no. 2, revealed a gap between declared policy and implementation. There is a detailed, declared policy of reform, and in examining the implementation process, as revealed in the in-depth interviews, a gap between decisions, deciders, declarations and actual execution i.e. receivers were identified. The following types of notable characteristics describing and defining this gap were found:

- $\quad$ characteristics linked to governmental components, including difficulties with governability owing to frequent changes in government, politics of internal struggles, problematic organizational structure and absence of legislation.

- characteristics referring to organizational components including a time dimension, prolonged reforms, public management culture of 'programs with a beginning and no end', absence of broad agreement among interested parties, lack of budgets for reform and absence of visibility, presence and marketing of the reform.

Findings Emerging from Research Question No 3: What constitutes the gap and how can it be bridged?

The picture emerging from the integrated findings to the third research question illustrate components of the gap between policy and its execution as well as indicating directions to bridge this gap:

- $\quad$ Components in the implementation process: employing mediating tools and political power to promote determined policy.

- $\quad$ Personal components: leadership, commitment, personal opinions and outlook, and reducing the gap between declaration and implementation in practice.

That is to say, bridging the gap between policy - deciders and implementation receivers demands resources, meaning implementation resources including legislation, budgets, organizational mechanisms, procedures and regulations that will allow 
implementation in the field as well as political forces pushing for implementation and enabling it to happen.

\section{Conclusion and recommendations}

The conclusions that emerged from this research enabled the development of a conceptual strategy for deciders, meaning politicians who deal with policy formulation processes, to determine policy that is more adjusted and has greater chances of being implemented in the field and being accepted by receivers with a minimum of gaps between declarations and actions in the field.

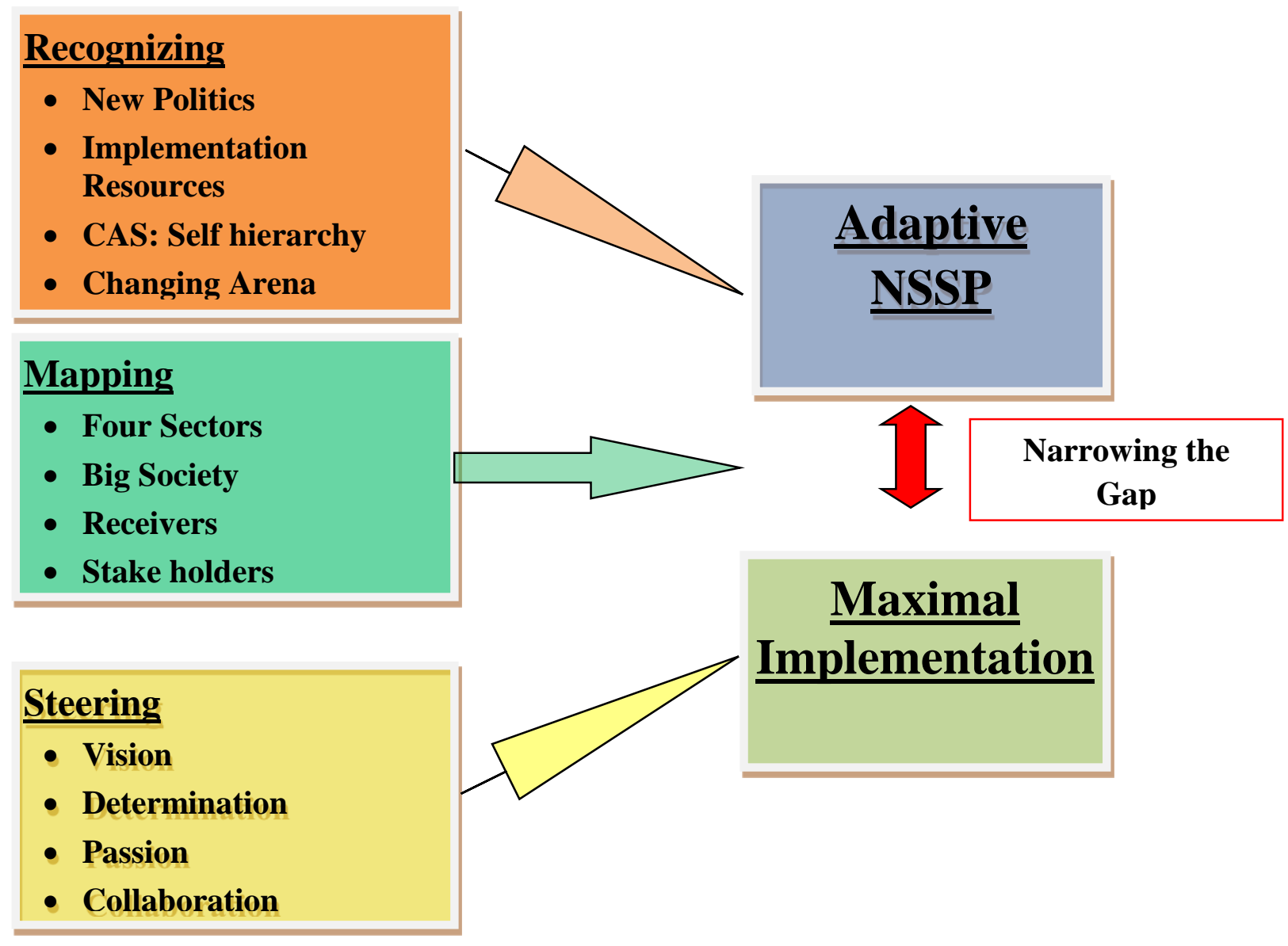

Figure 2: Strategy for narowing the gap between deciders and receivers

The strategy that emerged from the conclusions, aimed at narrowing the gap between deciders and receivers, proposes observing three processes: 
Issue no. $25 / 2018$

\section{Recognizing}

- "New politics" - deciders must recognize the facts and reality of changes in the political arena, routine dispersal of power to decide, and the existence of "new politics", which is no longer structured on left or right ideologies, politics of power divided among different parties, groups and organizations, politics in which it is possible to find simultaneously a variety of world-views and values in the same party or group. For example: attitudes rejecting governmental involvement in the economic market on the one hand, and ensuring citizens' rights on the other, a view that sees the state as responsible for living allowances for certain populations on the one hand, and strong pressures for people to work and earn their livelihood on the other. Just as today there is a concept of a mixed economy, so too is there a concept of 'mixed welfare'.

- Implementation resources - Recognizing the fact that allocating governmental resources for implementation is critical for the execution of policy in general and social services policy in particular. Implementation resources have been mentioned in studies and literature discussing policy implementation and in fact, this refers to a broad range of implementation resources: judicial resources (legislation, regulations, international treaties, international standards and control), human resources (allocating professionals both to lead implementation and to carry it out in the field - street level bureaucrats); budgetary resources to realize proposed policy and reform.

- $\quad$ CAS (Complex Adaptive System): Self Hierarchy - CAS argues that in circumstances of multiple actions, multiple participants, a sense of chaos and disorganization, hierarchies have neither the power nor the ability to restructure order. In this situation, the new order evolves by itself through environmental adjustments, an outcome of the interaction, power and actions of the involved. The new order creates a routine and new operational procedures adjusted to a multi participatory and operational arena.

- Changing arena - This is another outcome of globalization and neo-liberal economic approaches that have led to changes in the arena where political procedures and policy determination take place. There is enormous pressure to decentralize and delegate roles that were once the responsibility of the state, pressures for efficiency and reduction of governmental involvement, pressures to privatize and more. Deciders must acknowledge 
Issue no. $25 / 2018$

changing arenas, governmental and deciders' roles: the public sector is not necessarily meant to be the initiator, decider, determiner and executor. In the modern arena, consulting with all stakeholders, and mainly in the service provision area, is required to examine who the appropriate and correct authorities are, and which sector best executes policy to the satisfaction of receivers.

\section{Mapping}

The second process requires mapping, observation, review and recruitment of all those concerned with policy.

- $\quad$ Four Sectors - Mapping must include all four sectors existing in western societies: the public-governmental sector, the business-private sector, the third sector - all types of voluntary organizations, and the fourth sector - the sector of 'private' social entrepreneurs who offer non-profit services and responses.

- Civil society, the big society: in the spirit of individualism, encouragement for self-expression and diverse ideas, civil society must have a more significant, active and broader place in deciders' policy formulation processes.

- Receivers: this research emphasizes and places receivers at the center of public discussion about social services policy formulation and implementation. As customers for whom the policy is intended, it is important that their voices be heard more in policy formulation and implementation processes. Receivers can contribute authentic information from the reality of their lives, information that will help structure an appropriate, friendly, accessible policy that provides a real answer to the needs of customers as they experience them. Including customers can also help reduce their sense of alienation and threat, which were revealed during the research.

- Stakeholders: this concept refers to all interested parties, in the broadest sense of the concept. It is necessary to map all stakeholders concerned both with policy and its implementation, and make them partners from the first stages of planning and consideration. Stakeholders can be bodies, organizations and people directly concerned with policy or those concerned with certain interfaces of policy. The issue of social services, as detailed in the 
Issue no. $25 / 2018$

literature review also includes components of education, health, housing etc., and therefore it is important to include those interested parties in policy formulation processes. The integration and collaboration of many factors outside politics can also guarantee continuity in case of governmental turnover.

\section{Steering}

This stage deals with navigating and outlining the way to implementation, a process that expresses the movement of operational forces in the direction of execution and realization both in determining policy and its implementation.

- Vision: defining a clear focused vision that constitutes the 'northern star', supreme aim that is important for all those involved, and because of this importance, they unite and join forces to realize it. It is important that this stage includes public meetings, providing information, reducing senses of fear and/or withholding information, declaration of intent and aims. Providing information is also a type of public relations to advance policy and the vision leading implementation.

- Determination: Determination alongside vision transmit to both deciders and receivers a message of seriousness, responsibility and true commitment to realize policy implementation. Determination also constitutes modeling for all stakeholders, how they are expected to enter the policy formulation and implementation process. Determination must be expressed by all levels of deciders and implementers as one, to give it public and practical expression in the field.

- Passion: A dimension of passion and deep belief in policy and implementation expresses important commitment to the long term and complicated implementation processes. Passion is an important emotional form that drives receivers and mid-level personnel to be recruited to act, implement and believe in a policy's ideas. This is a stage when it is important to consolidate leadership that will lead procedures cooperatively and transparently.

- Collaboration: collaboration is one of the most significant core components in all three aforementioned dimensions: recognition, mapping and steering. In the complex and challenging world in which we live, in a reality of multiple opinions, ideas, initiatives, 
Issue no. $25 / 2018$

services, suppliers and more - collaboration between all these components is a significant and critical touchstone in the process of formulating and implementing policy. Collaboration also refers to inter-ministerial, inter-departmental and regional coordination and cooperation.

This being the case, the three dimensions appearing in the conceptual model, influence and lead deciders to sets more adaptive policy that meets real needs on the one hand, and to maximal implementation procedures on the other. These processes help to match and make actions accurate both at policy formulation and implementation stages, as well as recruiting many partners who support these actions, are committed to them, and as such become stakeholders in the policy being executed.

At this stage too, one must continue to carry on dialogue and ongoing dynamic clarifications between policy and implementation, while modifying policy based on the reality of implementation and changing environment. As long as it exists and works, dynamic clarification helps narrow the gap between deciders and receivers. This model allows deciders to evaluate both policy and how and to what extent it is implemented.

Understanding the components of the gap as emerging from the conclusions drawn from this research can assist in understanding and directing decision-makers, i.e. deciders, with regard to desirable actions that ought to be taken to narrow the gap. The gap, in fact, has a role in the implementation process. It is a kind of marker indicating where implementers are in the process of implementation, what their destination is and what actions will help them reach it.

Another insight emerging from the factual conclusions of this research is the existence of a parallel narrative between the macro and micro levels in the three foci studied here: policy determination processes, implementation processes and the existence of a gap. The parallel narrative appears between globalization/localization processes, central/local government, and deciders/receivers. The proposed model actually suggests the development of mechanisms that create links, interactions and communication between the parallels. These links may narrow the developing gap between policy and implementation. Identifying components and their characteristics within the parallel processes may point to directions of actions and intervention foci, where it will be possible to exert influence to narrow the gap and moderate its intensity. For example, one of the issues identified as being responsible for 
Issue no. $25 / 2018$

the gap is the governing top-down organizational structure in Israel, a centralized approach that creates a separation between deciders and receivers, and described by one interviewee as "detached from the field", and experienced by receives as "imperviousness and alienation", "They offer me what they have, not what I need."

Developing regular mutual ways of communicating, exchanging information, mutual learning and joint committees, involving civic society - is one mechanism that can create links between parallels, links that will create an interface around common goals and ideas, and build a joint task force that promotes social service policy and acts towards its implementation.

This can be illustrated through the metaphor of "Waze" or "GPS", which is the world's largest community based traffic and navigation application.

The idea underlying Waze is that in fact, the power is in the hands of all drivers and participants on different roads, and the regular reports each user shares through the social network with software that immediately translates this information into recommendations for roads to take. This information is immediately distributed to drivers. The application suggests several alternatives for reaching a destination, seeking to avoid blocks (traffic accidents or flooded roads, for example), so that everyone contributes to what transpires on the roads, and gets information that helps them reach their destination in the shortest and safest way. In fact, this is a whole social network, whose users do not necessarily know one another, but they all have the same goal: to get information about the shortest, fastest and safest routes to reach their chosen destinations. Cooperation in the social network provides each participant with a feeling of belonging and contribution to the task on the one hand, and the tangible product of available information that is meaningful in helping them reach their destinations on the other hand. The information they provide is valuable, and after being considered allows them to receive the valuable information that they need. The link between all stakeholders is another aspect based on a common idea: everyone reports / everyone receives / everyone benefits, and thus each participant gets to his or her destination. Participants realize there are several ways to reach a destination, even if routes require side roads, but the goal and destination do not change. 
Issue no. $25 / 2018$

The Waze model illustrates the advantages of cooperation, sharing, transparency, use of advanced technologies stemming from globalization, and proper use of decentralizing authority. Reducing centralization of central government, increasing delegation, sharing and reciprocity in decision-making processes and implementation on the part of all stakeholders in all sectors, may contribute to moderating and narrowing the gaps that develop between policy determination and implementation, and create a joint task force enlisted to the endeavor of promoting joint ideas in the field of social services. This may be a process that prolongs the road, but on the other hand, increases the chances of reaching the destination.

The reality of current politics is characterized by 'a new order' of governance without one clear model that represents the new politics and thus can be regarded as an 'era of post regular order'. These changes demand more flexible attitudes about policy making and the complex, dynamic environment that we live in. Politicians should recalibrate their knowledge, tools, language and recognize that politics extend beyond parliament and require collaborations and partnerships with parties, groups, stakeholders, organizations receivers and civil society. It is a challenge demanding more discussion, research and learning.

\section{References}

- CRESWELL, J.W. (2009). Research Design: Qualitative, Quantitative, and Mix Methods Approaches. Thousand Oaks: Sage

- $\quad$ CRESWELL, J. W. (2014). A concise introduction to mixed methods research. Sage Publications.

- $\quad$ DOOLEY, K. J. (1997). A complex adaptive systems model of organization change. Nonlinear dynamics, psychology, and life sciences, 1(1), 69-97

- $\quad$ KACEN L. \& KRUMER-NEVO (2010) Data analysis in qualitative research. BenGurion University of the Negev Press (In Hebrew)

- $\quad$ KRAFT, M.E. FURLONG, S.R. (2010). Public Policy, Washington DC: CQ Press

- MILES, M. B., \& HUBERMAN, A. M. (1994). Qualitative data analysis: A sourcebook. Beverly Hills: Sage Publications.

- $\quad$ PATTON, M.Q. (2002). Qualitative Research and Evaluation Methods $3^{\text {rd }}$ Ed. New York: Sage Publications 
- $\quad$ PIERSON, P. (2001). Coping with Permanent Austerity Welfare State Restructuring in Affluent Democracies. In: P. PIERSON (ed.) The New Politics of the Welfare State. Oxford: Oxford University Press.

- $\quad$ SCHNEIDER, M., SOMERS, M. (2006). Organizations as complex adaptive systems: Implications of complexity theory for leadership research. The Leadership Quarterly, 17(4), $351-365$

- $\quad$ SHKEDI A. (2003) Words of Meaning - Qualitative Research - Theory and Practice, Tel Aviv University: Ramot (in Hebrew)

- $\quad$ SHKEDI A. (2014). The Meaning behind the Words, Methodologies of Qualitative Research: Theory and Practice. Tel Aviv University: Ramot (in Hebrew)

- $\quad$ STARKE, P. (2006). The politics of welfare state retrenchment: A literature review. Social Policy and Administration, 40 (1): 104-120

- TZABAR BEN-YEHOSHUA. N. (2016). Traditions and Genres in Qualitative Research, Philosophies, Strategies and Advanced Tools, Tel-Aviv, Israel: Mofet Institute (In Hebrew),

- WEIBLE, C. M. (2007). An advocacy coalition framework approach to stakeholder analysis: Understanding the political context of California marine protected area policy. Journal of Public Administration Research and Theory, 17(1), 95-117.

- WEISS-GAL, I. \& GAL, J. (2011). Policy Practice in Social Work. Jerusalem: The Hebrew University: Magnes, pp.87-115

- $\quad$ YIN R.K. (1992). The Case Study Method as a Tool for Doing Evaluation. Current Sociology 40 (1) 119-137.

- $\quad$ http://www.molsa.gov.il/About/OfficePolicy/Documents/\%D7\%9E\%D7\%A1\%D7\%9 E\%D7\%9A\%20\%D7\%9E\%D7\%93\%D7\%99\%D7\%A0\%D7\%99\%D7\%95\%D7\%AA\%2020 $\underline{14-2018 \% 20-}$ \%20\%D7\%A8\%D7\%9E\%D7\%AA\%20\%D7\%90\%D7\%A4\%D7\%A2\%D7\%9C\%202\%20\%2027-2-14.pdf 